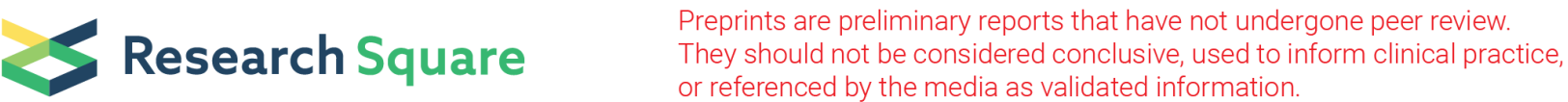

\section{Association of Single Nucleotide Polymorphisms With Insulin Secretion, Insulin Sensitivity, and Diabetes in Women With a History of Gestational Diabetes Mellitus}

\author{
Rashmi Prasad \\ Lund University \\ Karl Kristensen \\ Skåne University Hospital \\ Anastasia Katsarou \\ Lund University \\ Nael Shaat ( $\nabla$ nael.shaat@med.lu.se) \\ Lund University
}

\section{Research Article}

Keywords: Prediction of diabetes, Gestational diabetes, Genetics of type 2 diabetes, Insulin action, Insulin sensitivity

Posted Date: March 31st, 2021

DOI: https://doi.org/10.21203/rs.3.rs-358226/v1

License: (c) (i) This work is licensed under a Creative Commons Attribution 4.0 International License. Read Full License

Version of Record: A version of this preprint was published at BMC Medical Genomics on November 20th, 2021. See the published version at https://doi.org/10.1186/s12920-021-01123-6. 


\section{Abstract}

Aims: This study investigated whether single nucleotide polymorphisms (SNPs) reported by previous genome-wide association studies (GWAS) to be associated with impaired insulin secretion, insulin resistance, and/or type 2 diabetes are associated with disposition index, the homeostasis model assessment of insulin resistance (HOMA-IR), and/or development of diabetes following a pregnancy complicated by gestational diabetes mellitus (GDM).

Methods: Seventy-two SNPs were genotyped in 374 women with previous GDM from Southern Sweden. An oral glucose tolerance test was performed 1-2 years postpartum, although data on the diagnosis of diabetes were accessible up to 5 years postpartum. HOMA-IR and disposition index were used to measure insulin resistance and secretion, respectively.

Results: The risk A-allele in the rs 11708067 polymorphism of the adenylate cyclase 5 gene (ADCY5) was associated with decreased disposition index (beta $=-0.90, S E 0.38, p=0.019$ ). This polymorphism was an expression quantitative trait loci (eQTL) in islets for both $A D C Y 5$ and its antisense transcript. The risk C-allele in the rs2943641 polymorphism, near the insulin receptor substrate 1 gene (IRS1), was associated with increased HOMA-IR (beta $=0.36, S E 0.18, p=0.050$ ), and the T-allele of the rs4607103 polymorphism, near the ADAM metallopeptidase with thrombospondin type 1 motif 9 gene (ADAMTS9), was associated with postpartum diabetes ( $\mathrm{OR}=2.12, \mathrm{SE} 0.22, \mathrm{p}=0.00055)$. All analyses were adjusted for age, body mass index, and ethnicity.

Conclusions: This study demonstrated the genetic susceptibility of women with a history of GDM to impaired insulin secretion and sensitivity and, ultimately, to diabetes development.

\section{Introduction}

During pregnancy, insulin sensitivity progressively decreases, while associated insulin response increases by late gestation [1]. Gestational diabetes mellitus (GDM) develops when beta-cells cannot compensate for increased insulin resistance, despite the physiological changes related to glucose homeostasis during gestation [1]. Women with a history of GDM have a higher risk of developing type 2 diabetes [2] and metabolic syndrome [3] than those who were normoglycemic during pregnancy. Genetic risk factors related to progression to type 2 diabetes in women with a history of GDM have been previously studied by many research groups, including ours. Two polymorphisms (TCF7L2 rs 7903146 and FTO rs8050136) and a weighted risk score of type 2 diabetes risk alleles predict diabetes following GDM [4]. Other research groups have shown an association of the genetic risk score (GRS) with eventual progression to diabetes after GDM [5]. However, GRS could not predict the progression to diabetes in women with a history of GDM from the Diabetes Prevention Program (DPP) [6].

Type 2 diabetes is a growing global health concern and is caused by insulin resistance and beta-cell dysfunction [7]. Recent evidence suggests that both insulin secretion and resistance are heritable traits [8] and studies have also demonstrated a genetic contribution to defective insulin secretion and resistance in individuals with type 2 diabetes [9, 10].

Genome-wide association studies (GWAS) have revealed many genetic susceptibility loci for type 2 diabetes and related traits, such as insulin resistance and beta-cell dysfunction [10-15]. In addition, we have recently shown an association of the rs11708067 polymorphism in the ADCY5 (adenylate cyclase 5) gene with increased 2-h glucose levels and decreased homeostasis model assessment of beta-cell function (HOMA2-B) in Swedish women with GDM [16].

Only a few studies have examined the genetic susceptibility to postpartum diabetes in women with previous GDM $[4,17]$. In addition, the genetic architecture of postpartum diabetes and its related traits could differ between ethnicities. Thus, we sought to validate the association of single nucleotide polymorphisms (SNPs) from previous GWAS [10-15] with indices 
of beta-cell function, insulin resistance, and eventual progression to diabetes in a cohort of women from Southern Sweden with a history of GDM.

\section{Participants And Methods Participants}

Women delivering between 2003-2005 were invited to participate in the study in the County of Skane in Southern Sweden, as described previously [18]. GDM was diagnosed by a 75-g oral glucose tolerance test (OGTT) at the 28th and/or the 12th week of gestation for those with a first-degree relative with diabetes or previous GDM. Study participants were followed-up for development of diabetes using OGTT up to 5 years postpartum or until a diagnosis of diabetes; data were accessible through the primary care journals. GDM and diabetes were diagnosed according to the diagnostic criteria recommended by the WHO in 1999 [19]. Based on these criteria and the availability of stored DNA, a cohort of 374 women with previous GDM (57 of whom developed diabetes) were included in the present study.

\section{Glycaemic trait measurements}

Women underwent OGTT with measurements of both glucose and insulin concentrations at 0,30 , and 120 min to calculate indices of beta-cell function and insulin resistance, at 1-2 years postpartum, as reported previously [20]. Homeostasis model assessment of insulin resistance (HOMA-IR) was used to estimate insulin resistance (fasting serum insulin $\times$ fasting plasma glucose)/22.5 [21]. Insulin secretion capacity was estimated using the disposition index ([insulinogenic index (insulin $30 \mathrm{~min}-$ insulin $_{0 \mathrm{~min}}$ )/( glucose $_{30 \mathrm{~min}}-$ glucose $\left.\left._{0 \mathrm{~min}}\right)\right] /$ HOMA-IR) [22].

\section{Genotyping}

DNA was extracted from whole blood using the MaxiPrep Kit (QIAGEN, Sollentuna, Sweden). SNPs were genotyped using a Sequenom massARRAY platform or TaqMan allelic discrimination assay with an ABI Prism 7900 sequence detection system (Applied Biosystems, Foster City, CA, USA). The success rate of genotyping was $>90 \%$. Replication genotyping of $6 \%$ of the samples showed $>98 \%$ concordance. All SNPs were in Hardy-Weinberg equilibrium (HWE), except for rs11920090 and rs6467136, which significantly deviated in women who did not develop diabetes postpartum $(p<0.01)$, and were eventually excluded from the analysis. We analysed 12 SNPs previously shown to be associated with measures of insulin secretion $[11,12,14]$, and 4 SNPs previously shown to be associated with measures of insulin resistance in GWAS $[10,11,13]$, for association with disposition index and HOMA-IR, respectively, in women with previous GDM. We also analysed 70 (2 out of 72 were excluded for not being in HWE) SNPs, previously associated with diabetes in GWAS $[11,15,23]$, for association with diabetes postpartum.

\section{Exploration of expression quantitative trait loci (eQTLs)}

Polymorphisms associated with disposition index, HOMA-IR, or T2D were assessed for association with gene expression in human pancreatic islets in RNA-Seq data of 191 donors [24]. The data are uploaded to EGA (https://ega-archive.org/) with the following accession numbers: RNAseq: EGAS00001004042, GWAS: EGAS00001004044, and Phenotype: EGAS00001004056.

\section{Statistical analyses}

All statistical analyses were conducted using IBM SPSS Statistics for Windows, version 22.0 (Armonk, NY) and PLINK (version 1.07, http://pngu.mgh.harvard.edu/ purcell/plink/index.shtml). Generalized linear models with maximum likelihood estimates were used for estimating SNP associations with disposition index and HOMA-IR. Age, ethnicity, and body mass index (BMI) were used as covariates/confounders, and data are presented as beta estimates and standard errors (SE). Correction for multiple testing was performed using permutations. We applied a false discovery rate (FDR) for 
the association analysis of postpartum diabetes. Since it was a validation of previous associations, we considered $p \leq$ 0.05 as significant.

\section{Results}

\section{Clinical characteristics}

Clinical characteristics of the study subjects were detailed previously [25]. Mean (SE) age of the participants was 32.9 (0.25) years and mean BMI was $25.2(5.2) \mathrm{kg} / \mathrm{m}^{2}$. The study participants were of European (n) 286 [76.5\%] or nonEuropean (n) 77 [20.6\%] origin, and 11 [2.9\%] were unclassifiable.

\section{Association of SNPs with disposition index}

The risk A-allele of SNP rs 11708067 in the ADCY5 locus was associated with decreased disposition index (beta $=-0.90$, SE $0.38, p=0.019$ ) after adjustment for age, BMI, and ethnicity (Table 1). Interestingly, the rs 11708067 polymorphism was an eQTL for both $A D C Y 5$ and the antisense transcript for $A D C Y 5$ (Table 2). The ADCY5 rs11708067 genotype was also associated with 2-h glucose level, though only in the additive model (AG vs. GG: beta $=0.62, S E 0.33, p=0.06$; AA vs. GG: beta $=0.71$, SE 0.32, $p=0.027$ ).

Table 1

Single nucleotide polymorphisms with disposition index at 1-2 years postpartum in women with a history of gestational diabetes mellitus.

\begin{tabular}{|lllllll|}
\hline SNP & Locus & Location & CHR & EA & B (SE) & P-value \\
\hline rs11708067 & ADCY5 & Intron & 3 & A & $-0.90(0.38)$ & 0.019 \\
\hline rs340874 & PROX1 & Intergenic & 1 & C & $0.09(0.15)$ & 0.56 \\
\hline rs560887 & G6PC2/ABCB11 & Intron & 2 & C & $0.027(0.13)$ & 0.83 \\
\hline rs10885122 & ADRA2A & Intergenic & 10 & G & $-0.075(0.37)$ & 0.84 \\
\hline rs4607517 & GCK & Intergenic & 7 & A & $-0.005(0.17)$ & 0.98 \\
\hline rs2191349 & DGKB/TMEM195 & Intergenic & 7 & T & $-0.07(0.20)$ & 0.72 \\
\hline rs7034200 & GLIS3 & Intron & 9 & A & $-0.04(0.19)$ & 0.82 \\
\hline rs7944584 & MADD & Intron & 11 & A & $-0.24(0.28)$ & 0.40 \\
\hline rs174550 & FADS1 & Intron & 11 & T & $-0.001(0.13)$ & 0.99 \\
\hline rs10830963 & MTNR1B & Intron & 11 & G & $0.12(0.18)$ & 0.49 \\
\hline rs11605924 & CRY2 & Intron & 11 & A & $-0.60(0.32)$ & 0.064 \\
\hline rs7756992 & CDKAL1 & Intron & 6 & G & $-0.25(0.20)$ & 0.21 \\
\hline CHR = chromosome & EA = effect allele, B = beta/effect size, SE = standard error; significant p-values $(\leq 0.05)$ \\
\hline
\end{tabular}


Table 2

The rs 11708067 as an expression quantitative trait loci (eQTL) for both adenylate cyclase 5 (ADCY5) and the antisense transcript of $A D C Y 5$ in islets $(\mathrm{n}=191)$.

\begin{tabular}{|llllll|}
\hline SNP & Gene & Gencode ID & Beta & t_STAT & P-value \\
\hline rs11708067 & ADCY5_ANTISENSE TRANSCRIPT & ENSG00000272678 & 0.70 & 5.91 & $1.56 \mathrm{e}-08$ \\
\hline rs11708067 & ADCY5 & ENSG00000173175 & 0.45 & 3.63 & 0.00037 \\
\hline \multicolumn{2}{|l}{ SNP = single nucleotide polymorphism; -values $(\leq 0.05)$} & & & \\
\hline
\end{tabular}

\section{Association of SNPs with HOMA-IR}

The risk C-allele of the insulin receptor substrate-1 (IRS1) rs2943641 polymorphism was associated with increased HOMAIR (beta $=0.36$, SE 0.18, $p=0.050$ ) after adjustment for age, BMI, and ethnicity (Table 3). This SNP was an eQTL for the IRS1 gene in adipose tissue (from public data [https://gtexportal.org/]) (Table 4) [26].

Table 3

Association of single nucleotide polymorphisms (SNPs) with the homeostasis model assessment of insulin resistance (HOMA-IR) at 1-2 years postpartum in women with a history of gestational diabetes mellitus.

\begin{tabular}{|lllllll|}
\hline SNP & Locus & Location & CHR & EA & B (SE) & p-value \\
\hline rs2943641 & IRS1 & Intergenic & 2 & C & $0.36(0.18)$ & 0.050 \\
\hline rs4675095 & IRS1 & Intron & 2 & A & $-0.11(0.55)$ & 0.83 \\
\hline rs1801282 & PPARG & Coding - missense & 3 & C & $0.29(0.41)$ & 0.48 \\
\hline rs35767 & IGF1 & Near Gene-5 & 12 & G & $0.02(0.31)$ & 0.94 \\
\hline
\end{tabular}

$\mathrm{CHR}=$ chromosome, $\mathrm{EA}=$ effect allele, $\mathrm{B}=$ beta/effect size, $\mathrm{SE}=$ standard error; significant $p$-values $(\leq 0.05)$. HOMA-IR was normalized using rank normal transformation.

Table 4

The rs2943641 as an expression quantitative trait loci (eQTL) for the insulin receptor substrate 1 (IRS1) gene in adipose tissue [from The Genotype-Tissue Expression (GTEx) project].

\begin{tabular}{|llllllll|}
\hline Gencode ID & $\begin{array}{l}\text { Gene } \\
\text { Symbol }\end{array}$ & Variant ID & SNP ID & P-value & NES & Tissue \\
\hline ENSG00000169047.5 & IRS1 & chr2_226229029_T_C_b38 & rs2943641 & $1.4 \mathrm{e}-16$ & -0.30 & $\begin{array}{l}\text { Adipose - } \\
\text { Subcutaneous }\end{array}$ \\
\hline ENSG00000169047.5 & IRS1 & chr2_226229029_T_C_b38 & rs2943641 & $6.1 \mathrm{e}-12$ & -0.23 & $\begin{array}{l}\text { Adipose - } \\
\text { Visceral } \\
\text { (Omentum) }\end{array}$ \\
\hline ENSG00000272622.1 & $\begin{array}{l}\text { RP11- } \\
\text { 395N3.2 }\end{array}$ & chr2_226229029_T_C_b38 & rs2943641 & $3.5 \mathrm{e}-9$ & -0.23 & $\begin{array}{l}\text { Adipose - } \\
\text { Subcutaneous }\end{array}$ \\
\hline ENSG00000261379.1 & $\begin{array}{l}\text { RP11- } \\
\text { 395N3.1 }\end{array}$ & chr2_226229029_T_C_b38 & rs2943641 & $2.1 \mathrm{e}-7$ & -0.23 & $\begin{array}{l}\text { Adipose - } \\
\text { Subcutaneous }\end{array}$ \\
\hline ENSG00000272622.1 & $\begin{array}{l}\text { RP11- } \\
\text { 395N3.2 }\end{array}$ & chr2_226229029_T_C_b38 & rs2943641 & 0.0000023 & -0.19 & $\begin{array}{l}\text { Adipose - } \\
\text { Visceral } \\
\text { (Omentum) }\end{array}$ \\
\hline SNP = single nucleotide polymorphism, NES = normal effect size & & & & & & \\
\hline
\end{tabular}


The T-allele of rs4607103, near the ADAM metallopeptidase with thrombospondin type 1 motif 9 (ADAMTS9) gene, was associated with an increased risk of diabetes postpartum (OR for the C-allele 0.47 (Cl: 0.30-0.73), p = 0.00055; pFDR = 0.039 ) (Table 5). The CC carriers have more insulin resistance than TT carriers (beta $=-0.11, S E=0.05, p=0.036$ ). The women who developed diabetes postpartum had a lower disposition index (Mean = 3.01, SE 0.88 vs. 13.29, SE 0.87, $p \leq$ 0.0001 ), higher insulin resistance HOMA-IR (Mean $=3.20$, SE 0.26 vs. 1.69, SE 0.07, p $\leq 0.0001)$, and higher BMI (Mean = 30.48 , SE 0.82 vs. 24.29 , SE 0.25 , p $\leq 0.001$ ) (Table 6).

Table 5

Single nucleotide polymorphisms (SNPs) with nominal p-values for association with diabetes up to 5 years after a pregnancy complicated by gestational diabetes mellitus.

\begin{tabular}{|c|c|c|c|c|c|c|c|}
\hline SNP & $\begin{array}{l}\text { Gene/nearest } \\
\text { gene }\end{array}$ & Location & $\mathrm{CHR}$ & RAVOA & OR (Cl) & P-value & $\begin{array}{l}\text { P-value } \\
\text { (FDR_BH) }\end{array}$ \\
\hline \multirow[t]{2}{*}{ rs4607103 } & ADAMTS9-AS2 & Intron & 3 & $\mathrm{C} / \mathrm{T}$ & 0.47 & 0.00055 & 0.039 \\
\hline & & & & & $(0.30-0.73)$ & & \\
\hline \multirow[t]{2}{*}{ rs4607517 } & GCK & Intergenic & 7 & $A / G$ & 1.765 & 0.019 & 0.4902 \\
\hline & & & & & $(1.09-2.85)$ & & \\
\hline \multirow[t]{2}{*}{ rs1552224 } & CENTD2 & Intergenic & 11 & $\mathrm{~A} / \mathrm{C}$ & 2.22 & 0.024 & 0.4902 \\
\hline & & & & & $(1.09-4.61)$ & & \\
\hline \multirow[t]{2}{*}{ rs11634397 } & ZFAND6 & Intergenic & 15 & $\mathrm{G} / \mathrm{A}$ & 1.58 & 0.037 & 0.4902 \\
\hline & & & & & $(1.03-2.42)$ & & \\
\hline \multirow[t]{2}{*}{ rs7578597 } & THADA & Coding - missense & 2 & $\mathrm{~T} / \mathrm{C}$ & 3.29 & 0.037 & 0.4902 \\
\hline & & & & & $\begin{array}{l}(1.004- \\
10.75)\end{array}$ & & \\
\hline \multirow[t]{2}{*}{ rs4457053 } & ZBED3 & Intron of ZBED3- & 5 & $\mathrm{G} / \mathrm{A}$ & 1.56 & 0.041 & 0.4902 \\
\hline & & & & & $(1.02-2.38)$ & & \\
\hline
\end{tabular}


Table 6

Disposition index and homeostasis model assessment of insulin resistance in women who developed diabetes compared to that in women without diabetes postpartum.

\begin{tabular}{|llll|}
\hline Variable & $\begin{array}{l}\text { Women with postpartum diabetes } \\
\text { Mean (SE) }\end{array}$ & $\begin{array}{l}\text { Women without postpartum } \\
\text { diabetes } \\
\text { Mean (SE) }\end{array}$ & p-value \\
\hline Disposition index & $3.01(0.88)$ & $13.29(0.87)$ & $<0.0001$ \\
& $N(57)$ & $N(256)$ & \\
\hline HOMA-IR & $3.20(0.26)$ & $1.69(0.07)$ & $<0.0001$ \\
& $N(54)$ & $N(277)$ & $<0.001$ \\
\hline BMI & $30.48(0.82)$ & $24.29(0.25)$ & \\
\hline N = number of women, SE = standard error; significant p-value $(\leq 0.05)$ & $N(316)$ & \\
\hline
\end{tabular}

\section{Discussion}

In this study, we found an association between the risk A-allele of $A D C Y 5$ rs 11708067 and decreased disposition index derived from OGTT at 1-2 years postpartum in women with previous GDM. This was concordant with previous findings of an association of rs 11708067 with HOMA-B, a measure of insulin secretion [11], and the involvement of the $A D C Y 5$ gene in regulation of insulin secretion in pancreatic islet $\beta$-cells [27]. Previous studies reported reduced $A D C Y 5 \mathrm{mRNA}$ expression in islets due to risk alleles at rs 11708067 [28] and suggested that $A D C Y 5$ rs 11708067 is essential for coupling glucose to insulin secretion in human islets [28]. Wagner et al. implicated the rs11708067 polymorphism in defective proinsulin-to-insulin conversion [29]. Furthermore, rs 11708067 is an eQTL in islets for both ADCY5 and the antisense transcript for $A D C Y 5$ supports the role of this SNP in impairment of insulin secretion in women with previous GDM, thus increasing the risk of diabetes postpartum. We also found that the ADCY5 rs11708067 genotype was associated with 2-h glucose level, consistent with the previous results from our group [16] as well as others [11, 29].

Our analysis also identified an association of the risk C-allele of rs2943641 near the IRS1 gene with HOMA-IR in our cohort. IRS1 is a substrate of the insulin receptor tyrosine kinase, which plays a crucial role in the insulin signalling pathway and is expressed in insulin-sensitive tissues [30]. This finding agrees with an earlier study by Rung $\mathrm{J}$ et al., who reported an association of the C-allele of rs2943641 with measures of insulin resistance (HOMA-IR and ISI) and hyperinsulinemia in French, Danish, and Finnish participants from population-based cohorts [10]. Moreover, this SNP has been associated with type 2 diabetes in meta-analyses involving European [10] and Japanese participants [31]. Notably, rs2943641 is an eQTL for the IRS1 gene in adipose tissue. Thus, genetic variation near IRS1 may increase the risk of postpartum diabetes in women with previous GDM through increased insulin resistance.

Finally, we found that the T-allele of rs4607103, near the ADAMTS9 gene, could predict development of diabetes in our cohort. However, the risk allele in this study was opposite to that reported for diabetes [15]. Graae et al. showed that the Callele was associated with increased expression of secreted ADAMTS9 and decreased insulin sensitivity and signalling in human skeletal muscle [32]. Contrarily, in our data CC carriers seemed to have reduced insulin resistance compared to TT carriers, although there was no significant association. This phenomenon is not uncommon in genetics [33]; the actual functional variant in the ADAMTS9 region is not yet known, and the rs 4607103 polymorphism may be in a linkage disequilibrium with the functional variant in this region. Interestingly, the C-allele was associated with protection from type 2 diabetes in African Americans [34] but our study population was primarily European. Moreover, a potential gender effect 
could not be excluded [35]. Women who developed Diabetes were more likely to have severe beta-cell dysfunction and were unable to meet the demands of increased insulin resistance compared to those who did not develop diabetes postpartum. Therefore, women who developed diabetes postpartum could represent a unique subtype with a more severe beta-cell dysfunction than those with previous GDM who did not developed diabetes during the study period, which might also explain the protective effect of the rs 4607103 polymorphism. We do not have any data on the presence of antibodies in women who developed diabetes postpartum. Since approximately $1 \%$ of women with diabetes postpartum are diagnosed with type 1 diabetes postpartum in Sweden [36], the vast majority of women included in this study were expected to have been diagnosed with type 2 diabetes.

A strength of this study was the use of the disposition index, derived from OGTT, as a measure of beta-cell function adjusted for insulin resistance. The women in the study were followed up for development of diabetes up to 5 years postpartum. Our study provides novel insights into the genetic variants associated with postpartum diabetes and its related traits. A major weakness of the study was the failure to correct for multiple comparisons in the analyses, except for the analysis of development of diabetes after pregnancy. However, the analyses were adjusted for age, BMI, and ethnicity; permutations were performed to address the issue to a certain extent. The studied SNPs were previously shown to be associated with their respective traits, suggesting that this study could be considered a replication study. The study did not aim to detect small potential effects of the studied SNPs on insulin secretion and sensitivity.

In conclusion, we demonstrated the genetic susceptibility for impaired insulin secretion and sensitivity, as well as for the development of diabetes in women with a history of GDM. This finding could aid in the early identification of women at higher risk of developing diabetes postpartum.

\section{Declarations}

\section{Ethics approval and consent to participate}

The study was approved by the Ethics Committee of Lund University (LU 259-00) and written informed consent was obtained from all women included in the study.

\section{Consent for publication}

Not applicable.

\section{Availability of data and materials}

The datasets used and/or analysed during the current study are available from the corresponding author on reasonable request.

\section{Competing interests}

The authors declare that there is no conflict of interest associated with this manuscript.

\section{Authors contribution statement}

RPB and NS designed the study. RPB and NS wrote the first draft, reviewed and edited the manuscript. NS supervised the study. RPB performed the statistical analysis. AK and KK reviewed and edited the manuscript. NS is the guarantor of this work.

\section{Acknowledgments}


We gratefully acknowledge Maria Sterner, Malin Neptin, and Jasmina Kravic for their technical assistance, sampling, and organization of data. We also thank all the women participating in the study.

\section{Funding}

The study was supported by grants from the Research Funds of Skåne University Hospital and the Skåne County Council's Research and Development Foundation. The funders had no role in study design, data collection and analysis, decision to publish, or preparation of the manuscript.

\section{References}

1. Catalano PM. Trying to understand gestational diabetes. Diabet Med. 2014;31(3):273-81. Epub 2013/12/18. doi: 10.1111/dme.12381. PubMed PMID: 24341419; PubMed Central PMCID: PMCPMC4178541.

2. Bellamy L, Casas JP, Hingorani AD, Williams D. Type 2 diabetes mellitus after gestational diabetes: a systematic review and meta-analysis. Lancet. 2009;373(9677):1773-9. doi: 10.1016/S0140-6736(09)60731-5. PubMed PMID: 19465232.

3. Lauenborg J, Mathiesen E, Hansen T, Glumer C, Jorgensen T, Borch-Johnsen K, et al. The prevalence of the metabolic syndrome in a danish population of women with previous gestational diabetes mellitus is three-fold higher than in the general population. J Clin Endocrinol Metab. 2005;90(7):4004-10. Epub 2005/04/21. doi: 10.1210/jc.2004-1713. PubMed PMID: 15840755.

4. Ekelund M, Shaat N, Almgren P, Anderberg E, Landin-Olsson M, Lyssenko V, et al. Genetic prediction of postpartum diabetes in women with gestational diabetes mellitus. Diabetes Res Clin Pract. 2012;97(3):394-8. Epub 2012/05/18. doi: 10.1016/j.diabres.2012.04.020. PubMed PMID: 22591707.

5. Li M, Rahman ML, Wu J, Ding M, Chavarro JE, Lin Y, et al. Genetic factors and risk of type 2 diabetes among women with a history of gestational diabetes: findings from two independent populations. BMJ Open Diabetes Res Care. 2020;8(1). Epub 2020/01/21. doi: 10.1136/bmjdrc-2019-000850. PubMed PMID: 31958311; PubMed Central PMCID: PMCPMC7039588.

6. Sullivan SD, Jablonski KA, Florez JC, Dabelea D, Franks PW, Dagogo-Jack S, et al. Genetic risk of progression to type 2 diabetes and response to intensive lifestyle or metformin in prediabetic women with and without a history of gestational diabetes mellitus. Diabetes Care. 2014;37(4):909-11. Epub 2013/11/26. doi: 10.2337/dc13-0700. PubMed PMID: 24271189; PubMed Central PMCID: PMCPMC3964494.

7. DeFronzo RA, Ferrannini E, Groop L, Henry RR, Herman WH, Holst JJ, et al. Type 2 diabetes mellitus. Nat Rev Dis Primers. 2015;1:15019. Epub 2015/01/01. doi: 10.1038/nrdp.2015.19. PubMed PMID: 27189025.

8. Poulsen P, Levin K, Petersen I, Christensen K, Beck-Nielsen H, Vaag A. Heritability of insulin secretion, peripheral and hepatic insulin action, and intracellular glucose partitioning in young and old Danish twins. Diabetes. 2005;54(1):27583. Epub 2004/12/24. doi: 10.2337/diabetes.54.1.275. PubMed PMID: 15616039.

9. Lyssenko V, Nagorny CL, Erdos MR, Wierup N, Jonsson A, Spegel P, et al. Common variant in MTNR1B associated with increased risk of type 2 diabetes and impaired early insulin secretion. Nat Genet. 2009;41(1):82-8. Epub 2008/12/09. doi: 10.1038/ng.288. PubMed PMID: 19060908; PubMed Central PMCID: PMCPMC3725650.

10. Rung J, Cauchi S, Albrechtsen A, Shen L, Rocheleau G, Cavalcanti-Proenca C, et al. Genetic variant near IRS1 is associated with type 2 diabetes, insulin resistance and hyperinsulinemia. Nat Genet. 2009;41(10):1110-5. Epub 2009/09/08. doi: 10.1038/ng.443. PubMed PMID: 19734900.

11. Dupuis J, Langenberg C, Prokopenko I, Saxena R, Soranzo N, Jackson AU, et al. New genetic loci implicated in fasting glucose homeostasis and their impact on type 2 diabetes risk. Nat Genet. 2010;42(2):105-16. Epub 2010/01/19. doi: 10.1038/ng.520. PubMed PMID: 20081858; PubMed Central PMCID: PMCPMC3018764. 
12. Steinthorsdottir V, Thorleifsson G, Reynisdottir I, Benediktsson R, Jonsdottir T, Walters GB, et al. A variant in CDKAL1 influences insulin response and risk of type 2 diabetes. Nat Genet. 2007;39(6):770-5. Epub 2007/04/27. doi: 10.1038/ng2043. PubMed PMID: 17460697.

13. Diabetes Genetics Initiative of Broad Institute of H, Mit LU, Novartis Institutes of BioMedical R, Saxena R, Voight BF, Lyssenko V, et al. Genome-wide association analysis identifies loci for type 2 diabetes and triglyceride levels. Science. 2007;316(5829):1331-6. Epub 2007/04/28. doi: 10.1126/science.1142358. PubMed PMID: 17463246.

14. Prokopenko I, Langenberg C, Florez JC, Saxena R, Soranzo N, Thorleifsson G, et al. Variants in MTNR1B influence fasting glucose levels. Nat Genet. 2009;41(1):77-81. Epub 2008/12/09. doi: 10.1038/ng.290. PubMed PMID: 19060907; PubMed Central PMCID: PMCPMC2682768.

15. Zeggini E, Scott LJ, Saxena R, Voight BF, Marchini JL, Hu T, et al. Meta-analysis of genome-wide association data and large-scale replication identifies additional susceptibility loci for type 2 diabetes. Nat Genet. 2008;40(5):638-45. Epub 2008/04/01. doi: 10.1038/ng.120. PubMed PMID: 18372903; PubMed Central PMCID: PMCPMC2672416.

16. Arora GP, Akerlund M, Brons C, Moen GH, Wasenius NS, Sommer C, et al. Phenotypic and genotypic differences between Indian and Scandinavian women with gestational diabetes mellitus. J Intern Med. 2019;286(2):192-206. Epub 2019/03/29. doi: 10.1111/joim.12903. PubMed PMID: 30919529.

17. Kwak SH, Choi SH, Kim K, Jung HS, Cho YM, Lim S, et al. Prediction of type 2 diabetes in women with a history of gestational diabetes using a genetic risk score. Diabetologia. 2013;56(12):2556-63. Epub 2013/09/24. doi: 10.1007/s00125-013-3059-x. PubMed PMID: 24057154.

18. Anderberg E, Landin-Olsson M, Kalen J, Frid A, Ursing D, Berntorp K. Prevalence of impaired glucose tolerance and diabetes after gestational diabetes mellitus comparing different cut-off criteria for abnormal glucose tolerance during pregnancy. Acta Obstet Gynecol Scand. 2011;90(11):1252-8. doi: 10.1111/j.1600-0412.2011.01214.x. PubMed PMID: 21679163.

19. World Health Organization. Definition, diagnosis and classification of diabetes mellitus and its complications : report of a WHO consultation. Part 1, Diagnosis and classification of diabetes mellitus. World Health Organization. 1999.

20. Ignell C, Shaat N, Ekelund M, Berntorp K. The impact of ethnicity on glucose homeostasis after gestational diabetes mellitus. Acta Diabetol. 2013;50(6):927-34. doi: 10.1007/s00592-013-0484-8. PubMed PMID: 23732816.

21. Matthews DR, Hosker JP, Rudenski AS, Naylor BA, Treacher DF, Turner RC. Homeostasis model assessment: insulin resistance and beta-cell function from fasting plasma glucose and insulin concentrations in man. Diabetologia. 1985;28(7):412-9. PubMed PMID: 3899825.

22. Jensen CC, Cnop M, Hull RL, Fujimoto WY, Kahn SE, American Diabetes Association GSG. Beta-cell function is a major contributor to oral glucose tolerance in high-risk relatives of four ethnic groups in the U.S. Diabetes. 2002;51(7):21708. PubMed PMID: 12086947.

23. Voight BF, Scott LJ, Steinthorsdottir V, Morris AP, Dina C, Welch RP, et al. Twelve type 2 diabetes susceptibility loci identified through large-scale association analysis. Nat Genet. 2010;42(7):579-89. Epub 2010/06/29. doi: 10.1038/ng.609. PubMed PMID: 20581827; PubMed Central PMCID: PMCPMC3080658.

24. Asplund OPS, Emilia Ottosson-Laakso, Ulrika Krus, Olle Korsgren, Hindrik Mulder, Erik Renstrom, Ola Hansson, Leif Groop, Rashmi B Prasad. Islet Gene View - a tool to facilitate islet research. bioRxiv.

2019;https://www.biorxiv.org/content/10.1101/435743v2.full.

25. Shaat N, Ignell C, Katsarou A, Berntorp K. Glucose homeostasis, beta cell function, and insulin resistance in relation to vitamin D status after gestational diabetes mellitus. Acta Obstet Gynecol Scand. 2017;96(7):821-7. doi: 10.1111/aogs.13124. PubMed PMID: 28276579.

26. Consortium GT. The Genotype-Tissue Expression (GTEx) project. Nat Genet. 2013;45(6):580-5. Epub 2013/05/30. doi: 10.1038/ng.2653. PubMed PMID: 23715323; PubMed Central PMCID: PMCPMC4010069.

Page 10/11 
27. Shibasaki T, Sunaga Y, Seino S. Integration of ATP, cAMP, and Ca2+ signals in insulin granule exocytosis. Diabetes. 2004;53 Suppl 3:S59-62. Epub 2004/11/25. doi: 10.2337/diabetes.53.suppl_3.s59. PubMed PMID: 15561922.

28. Hodson DJ, Mitchell RK, Marselli L, Pullen TJ, Gimeno Brias S, Semplici F, et al. ADCY 5 couples glucose to insulin secretion in human islets. Diabetes. 2014;63(9):3009-21. Epub 2014/04/18. doi: 10.2337/db13-1607. PubMed PMID: 24740569; PubMed Central PMCID: PMCPMC4141364.

29. Wagner R, Dudziak K, Herzberg-Schafer SA, Machicao F, Stefan N, Staiger H, et al. Glucose-raising genetic variants in MADD and ADCY5 impair conversion of proinsulin to insulin. PLoS One. 2011;6(8):e23639. Epub 2011/09/03. doi: 10.1371/journal.pone.0023639. PubMed PMID: 21887289; PubMed Central PMCID: PMCPMC3161735.

30. Boucher J, Kleinridders A, Kahn CR. Insulin receptor signaling in normal and insulin-resistant states. Cold Spring Harb Perspect Biol. 2014;6(1). Epub 2014/01/05. doi: 10.1101/cshperspect.a009191. PubMed PMID: 24384568; PubMed Central PMCID: PMCPMC3941218.

31. Ohshige T, Iwata M, Omori S, Tanaka Y, Hirose H, Kaku K, et al. Association of new loci identified in European genomewide association studies with susceptibility to type 2 diabetes in the Japanese. PLoS One. 2011;6(10):e26911. Epub 2011/11/03. doi: 10.1371/journal.pone.0026911. PubMed PMID: 22046406; PubMed Central PMCID: PMCPMC3202571.

32. Graae AS, Grarup N, Ribel-Madsen R, Lystbaek SH, Boesgaard T, Staiger H, et al. ADAMTS9 Regulates Skeletal Muscle Insulin Sensitivity Through Extracellular Matrix Alterations. Diabetes. 2019;68(3):502-14. Epub 2019/01/11. doi: 10.2337/db18-0418. PubMed PMID: 30626608; PubMed Central PMCID: PMCPMC6385758.

33. Lin PI, Vance JM, Pericak-Vance MA, Martin ER. No gene is an island: the flip-flop phenomenon. Am J Hum Genet. 2007;80(3):531-8. Epub 2007/02/03. doi: 10.1086/512133. PubMed PMID: 17273975; PubMed Central PMCID: PMCPMC1821115.

34. Cooke JN, Ng MC, Palmer ND, An SS, Hester JM, Freedman BI, et al. Genetic risk assessment of type 2 diabetesassociated polymorphisms in African Americans. Diabetes Care. 2012;35(2):287-92. Epub 2012/01/26. doi: 10.2337/dc11-0957. PubMed PMID: 22275441; PubMed Central PMCID: PMCPMC3263882.

35. Khramtsova EA, Davis LK, Stranger BE. The role of sex in the genomics of human complex traits. Nat Rev Genet. 2019;20(3):173-90. Epub 2018/12/26. doi: 10.1038/s41576-018-0083-1. PubMed PMID: 30581192.

36. Dereke J, Nilsson C, Strevens H, Landin-Olsson M, Hillman M. IgG4 subclass glutamic acid decarboxylase antibodies (GADA) are associated with a reduced risk of developing type 1 diabetes as well as increased C-peptide levels in GADA positive gestational diabetes. Clin Immunol. 2016;162:45-8. Epub 2015/11/10. doi:

10.1016/j.clim.2015.11.001. PubMed PMID: 26548838.

Page $11 / 11$ 